\title{
Darwin Rocks Hegel: Does Nature Have a History?
}

\section{David Kolb}

In the popular press and the halls of politics, controversies over evolution are increasingly strident these days. Hegel is relevant in this connection, even though he rejected the theories of evolution he knew about, because he wants rational understanding and a larger process to comprehend natural processes and their history, but without any claims for intelligent design. The way current debates get publicised, there appear to be two extreme positions. The first is a reductionist materialism: all complex systems are describable purely in terms of the qualities of their most basic components, and the systems themselves result from Darwinian selection. No teleological concepts at all need be applied. At the other extreme is total teleology; all systems and their interactions and development are the result of preconceived conscious purposeful design by a powerful designer. The ontological status of the designer is usually filled out with theological notions.

Both extremes are overstated. The theology of an omnipotent designer is unnecessary, since, as Hume pointed out, even if you could argue from an effect to a designer, this would license only an inference to a designer intelligent and powerful enough to have produced the particular design being considered. And, given nature's abundant evidences of mediocre design - designs that satisfice, not optimise - there would be little likelihood that full-blown theological notions would have to be invoked. On the other hand Darwinian evolution need not reject all teleological concepts. Indeed, it shows how teleological systems can arise out of non-teleological interactions. Eyes and legs are for seeing and walking, in a sense Aristotle would accept. The Darwinist position may be extended to cover any determinate entity or process on any level. It is worth specifying what is meant here by 'content', especially because the examples that follow, which are intended as illustration of content, are so disparate. Presumably, this is what makes the position radical, but this can do with some emphasis perhaps: there may be selection on the level of biological systems and cultural systems, genes and memes. Even conscious thoughts and decisions can be seen, in Nietzschean fashion, as resulting from something like competition and selection on a preconscious level. Whether or not Darwinism is extended that far, it remains opposed to any theory of design.

\section{Aristotle}

It is worthwhile pausing for a moment with Aristotle, the master of teleology. In his Encyclopedia Logic ${ }^{1}$ Hegel remarks that Aristotle did not deny Plato's theory of Forms, but rather insisted that the forms have to be actualised. Aristotle had criticised Plato: 
Above all one might discuss the question what on earth the Forms contribute to sensible things... For they cause neither movement nor any change in them. But again they help in no wise either towards the knowledge of the other things (for they are not even the substance of these, else they would have been in them), or towards their being, if they are not in the particulars which share in them...And to say that they are patterns and the other things share in them is to use empty words and poetical metaphors. For what is it that works [to ergazomenon], looking to the Ideas? ...In the Phaedo the case is stated in this way-that the Forms are causes both of being and of becoming; yet when the Forms exist, still the things that share in them do not come into being, unless there is something to originate movement. (Aristotle, Metaphysics i.9, 991a7-23)

Hegel commented on this criticism:

Although actuality certainly is the principle of this Aristotelian philosophy, it is not the vulgar actuality of what is immediately at hand, but the Idea as actuality. Where then lies the controversy of Aristotle against Plato? It lies in this: Aristotle calls the Platonic Idea a mere dynamis, and establishes in opposition to Plato that the Idea, which both equally recognise to be the only truth, is essentially to be viewed as an energeia, in other words, as the inward that is totally to the fore, so that it is the unity of inner and outer. In other words the Idea should be regarded as actuality, in the emphatic sense here given to the word. (E 142a).

The Forms are active, at work, ergazomenon, en ergoi, energeia, werkend, wirklich. It is this which comes up against evolution as the contingent production of forms. The form of something, for Aristotle, is that which unifies, defines, opens, and sets boundaries to the thing's dispositions. Forms are neither separate 'things' from what they form, nor just summaries of their current configurations. One way to think of them is as what is passed on by causal influence or reproduction.

Aristotle insists that the forms of things are not just accidental products of the chance collocation of atoms. If that were the case, as Leucippus and Democritus claim, then he thinks that the regular and teleologically sophisticated operations of nature would be inexplicable, since chance would not account for the regularity and teleology evident in natural cycles and processes:

It is a wrong assumption to suppose universally that we have an adequate first principle in virtue of the fact that something always is so or always happens so. Thus Democritus reduces the causes that explain nature to the fact that things happened in the past in the same way as they 


\section{David Kolb}

happen now, but he does not think fit to seek for a first principle to explain this 'always'. So, while his theory is right in so far as it is applied to certain individual cases, he is wrong in making it of universal application. (Physics viii 1, 252a32-252b2).

Aristotle knew of Empedocles's theory that all kinds of mixtures of organs and animate parts were produced and only those fittest to survive did so. Aristotle rejected that theory because organisms have unified forms and teleologically coordinated processes. Those unified forms have no historical origin. Aristotle holds that activity is prior to potentiality. An organism is generated from another that possesses the same form already actualised:

For from the potentially existing the actually existing is always produced by an actually existing thing, e.g. man from man, musician by musician; there is always a first mover, and the mover already exists actually. We have said in our account of substance that everything that is produced is something produced from something and by something of the same species as it (Metaphysics ix.8, 1049b23-27)

So new species cannot arise, for where would their forms be already in act so as to be passed on? Artists and designers may produce new forms that are conceived first in their minds, but their products are not natural, self-moving.

It will be helpful later on to recall that there is no overall history in Aristotle's world. The world is eternal and its repertory of species stays the same throughout time. Aristotle has arguments against a beginning and end of time, as well as his familiar arguments that ultimately some pure actuality is needed for the world to be as it is. In social matters, too, Aristotle does not demand large scale teleology. There are many kinds of state and Aristotle discusses which are better than others and the ways in which they can change into one another, but he does not presume that history has any teleological direction towards (or away from) the best state. History wanders about in the limited space of social forms. This has some analogies to the way Hegel approaches nature as working within a set inventory of general forms. ${ }^{2}$

\section{Darwin and Hegel}

Darwin offers a mechanism that generates teleology out of non-teleology. Teleologically unified species emerge, but their emergence is not a teleological process. Variation and selection are uncoupled. Contingent variations meet contingent environments, adaptations get selected, systems that have teleological efficiency get created and selected for. This play of contingencies is what Intelligent Design attacks. Even religious believers who accept evolution, such as at least one of the Catholic positions, still insist that the overall process has to be 'more than chance.' Something has 


\section{Darwin Rocks Hegel: Does Nature Have a History?}

to hold the process together; usually this is said to be an overriding intention. Something has to comprehend and unite the events and stages of the process and make it a development rather than a wandering. Apart from Intelligent Design, many others have theories of a self-organising tendency in the universe to increase complexity, or even to move toward consciousness and intelligence. Hegel is relevant to this discussion because he too wants something, though not an intention, to comprehend and in some sense form or guide the natural processes. Explicating that 'in some sense' is one task of this paper.

Hegel speaks of his theory as similar to Aristotle's notions of potentiality and actuality. I will argue below that there is a sense in which Hegel agrees with Aristotle that actuality is prior, but Hegel does not think that this implies prior actual individuals of the same species. Is Hegel then providing a middle way in current debates, or is he a last gasp of the older way of thinking? As usual with Hegel, he is a bit of both. The key is found in the role of the Absolute Idea in the Logic. The Idea is the retrospective completion of the logical sequence of categories, the interrelated set of categories expressing the different moments and method of thought's self-development. It is the self-developed concept of being, the rational structure of thought and being. (Among other things it contains the overreaching of that duality.) If the Idea is the architecture of the processes of thought, everything will be thought through those categories, and if the structure of thought and reality are not separate, then everything will be according to those categories. In some sense everything that develops is already there 'in the Idea ' - but it what sense? 3

\section{Geological History}

I want to begin by considering what Hegel has to say about geology and the history of the earth, since there he does admit that the present features of the earth resulted from transformative events in the past. By the time Hegel was writing, scientists were becoming increasingly familiar with the existence of different kinds of rocks, with strata that looked as if they had been laid down in sequence on top of one another, and with a variety of fossilised animals and plants, many of which did not resemble currently living creatures. Some of these extinct animals and plants seemed as developed as current ones, others seemed more primitive. Geology seemed to present both a series of contemporary forms and a chronological record that might be seen as a process of emergence. ${ }^{4}$

The chief geological controversy Hegel knew of was between the Vulcanists and the Neptunists. Both sides held that catastrophic geological changes in the distant past had shaped what was seen today. The Vulcanists held that the main agency had been volcanic eruptions; the Neptunists argued for huge floods. The geological record seemed to provide evidence for both positions, and Hegel agreed that both mechanisms had been likely at work. So Hegel admits past processes and events that have given rise to the currently presented suite of rock strata and landforms: 


\section{David Kolb}

It is immediately evident . . . that the earth has had a history, i.e. that its constitution is the result of successive changes, the direct evidence of this is in this constitution itself. It points to a series of tremendous revolutions belonging to a remote past, and which probably also have a cosmic connection, in that the position of the earth with regard to the angle made by the axis with its orbit could have been altered. The surface of the earth bears evidence of its having supported a vegetation and an animal world which are now extinct (a) at great depth, (b) in huge stratifications, ( ) in localities where these species of animals and plants do not thrive. (E 339a)

Significantly, though, Hegel finds these past events to be of no philosophical interest. Chronology by itself explains nothing:

All of this is a matter of history, and has to be accepted as fact [ . . . This mere 'happening', which involves only a difference of time, this temporal succession of the strata, does not explain anything at all; or rather it completely ignores the necessity of the process, the comprehension of it [ .. ] This transformation has really no rational interest. The process has no other content than the product ... One can have interesting thoughts about the long intervals between such revolutions, about the profounder revolutions caused by alterations of the earth's axis, and also those caused by the sea. They are, however, hypotheses in the historical field, and this point of view of a mere succession in time has no philosophical significance whatever. (E 339a)

What is important philosophically is the existing repertory of types and forms, not the events in their temporal sequence of production:

The point of interest is not to determine how things were millions of years ago (and in the matter of years one can be generous); the interest is confined to what is there before us - to this system of distinct formations. [ ... The significance of the process is the intrinsic connection or necessary relation of these formations, and here succession in time plays no part. The universal law of this sequence may be understood without reference to its historical form. (E 339a)

Philosophical comprehension arises when we look at the present types and layers of rocks and see in them traces of the dialectic of the Concept and Idea: ${ }^{5}$

In the study of geology then, we must first direct our attention to the general mass of rocks and the Concept of the moments, rather than thoughtlessly enumerate the different kinds, straightway converting a small 
difference into a fresh genus or species. What is most important is to follow the transitions from one layer to another. Nature keeps to this order only in a general way and numerous variations occur, although the basic features of the order persist. Heim, with a truly philosophical view of the matter, has very clearly exhibited this transition, the breaking forth of one rock in another. (E 340aJ) ${ }^{6}$

We might summarise his point this way: nature has no history, even if it has a history:

The universal, absolute process is the process of the Idea, process in and for itself, through which the earth is created and preserved. But the creation is eternal, it is not an event which once happened; it is an eternal generation, for the infinite creative power of the Idea is a perennial activity. We do not, therefore, see in Nature the coming-to-be of the universal; that is, the universal side of Nature has no history. The sciences, political constitutions, etc., on the other hand, have a history, for they are the universal in the sphere of Spirit. [ ... ] There were events which shaped the present earth, but that becoming of the earth occurred in a kind of absolute Past, something over and done with, which has now produced the repertory of rock types that reveal the moments of the Idea. Formerly, history applied to the earth, but now it has come to a halt: a life which, inwardly fermenting, had Time within its own self; the Earth-spirit which has not yet reached the stage of opposition - the movement and dreaming of one asleep, until it awakes and receives its consciousness in Man, and so confronts itself as a stabilised formation. (E339aJ)

Nature is the realm of externality and separation. Separated moments of the Idea exist scattered about in space. If temporal processes brought them about, that is a contingent detail; what is important is the current set of types. This resembles what Aristotle says about cities and their history.

However, something is missing from Hegel's discussion of geology, something that James Hutton had already published in 1795. Hutton could be classified as a Vulcanist, but what is crucial here is that he espoused uniformitarianism. He argued that the present form of the earth results mostly from the same processes we see before us now, the slow erosion of hills and gradual uplifts and shifts along faults (and today we would add plate movements). The present is no different from the past and, most important, what we see today is not a final result, only a stage in a continuing process; today's forms have no permanence and no special finality (in either sense of that word).

Hegel would not favour this view, because he wants to maintain a distinction between the past processes, whatever they were, and the present 'final' spectrum of forms that can be analysed on their own. It would not help his purposes to view the 


\section{David Kolb}

current set of rock types and strata as merely a snapshot of the current results of ongoing processes. For then there could be no secure inventory of types to analyse, unless empirically doubtful Aristotelian claims were made about their invariance across the temporal processes. The same is true of organic forms. The theories of evolution Hegel knew about were all theories of development culminating in humanity. They too put development in the past. The uniformitarianism of Darwin's natural selection, where gene frequencies are always changing, refuses the present any teleological finality and make it just a temporary result of ongoing processes of change. I argue below that Hegel could accept this for much of the contingent detail of the natural world, but not for its skeleton of basic types.

\section{Spirit's History}

In contrast to his approach to geology, which admits only a Past that is not philosophically relevant, in the Phenomenology of Spirit, Hegel finds a history that is essential to spirit's development. Oddly enough, for Hegel the reason Spirit has a history, and the reason nature does not, are the same; that the moments of the Idea need to be posited and re-appropriated.

At every level, the logically necessary moments need to be posited and let flower, then appropriated into the whole that is both unified and differentiated. In Spirit this happens by different social and individual shapes arising and being superseded within the same spiritual unities. In nature, on the other hand, the realm of externality, the necessary moments are spread about in space distinct from one another. They are not brought together on their own but only by the development of conscious Spirit. Yet nature's externality is itself a necessary moment in Spirit's self-development; nature provides the stable background and immediacy that is required for Spirit's active positing and assimilating of its various moments as its interiorising and totalising process becomes transparent to itself. For society and culture not only is there a history, there is an active appropriation of that history as such. How does this process of internalising development happen? That is a large topic, but a few points are appropriate here. The form of Spirit's movement is described in the Logic, where pure categories transform into and come to include one another in increasingly complex assimilations and mediations and new unities. How this relates to the empirical givens of nature and history is one of the hardest parts of Hegel to understand, and this essay is an exercise in that direction.

The key is that nature and history are the Dasein and Wirklichkeit of the logical categories, their working existence and actuality. As Hegel said in his comment above about Aristotle and Plato, the Idea is not some higher level entity working over a lower level of beings. The Idea exists actively in and as those beings. How this happens for culture we can see in the Phenomenology of Spirit. Realising a cultural form of Spirit, making it wirklich, actual, in action, working itself out, brings tensions and conceptual difficulties that lead to internal problems and negations, which end up defining a new cultural form. 
Given a constellation of roles and goals and values, some new formation of roles and values and goals becomes possible and inevitable, though just how or through whom and when it happens is contingent. Because spirit is embodied there will be contingent and external historical details. For instance the internal tensions within the form of spirit embodied in the Roman republic needed for their resolution Julius Caesar, or someone like him. There is historical contingency within overall necessity. ${ }^{7}$

\section{Hegel and the Contingencies of Evolution}

Could this movement of Spirit be used to discuss the evolution of animal species? Early in his Philosophy of Nature, Hegel rejects the evolutionary ideas current at his time:

The Concept timelessly and in a universal manner posits all particularity in existence. It is a completely empty thought to represent species as developing successively, one after the other, in time It is this very fact of imagining a series of stages and the like, which has been such a hindrance to any progress in understanding the necessity of the various forms in nature. $(\text { E } 249)^{8}$

Along with Linnaeus and many contemporary biologists Hegel rejected the evolutionary schemes that he had heard of, which were tied to controversies in embryology. ${ }^{9}$ The theories he knew described the emergence of the organic from the inorganic, and represented the process as generic or unspecified organisms gradually acquiring specification. The movement was from generic to particular, as opposed to Darwin's movement from a particular to a new particular that might come to be a new species or genus. Hegel describes nature this way:

The eternal life of Nature consists in this: first, that the Idea displays itself in each sphere so far as it can within the finitude of that sphere, just as each drop of water provides an image of the sun, and secondly, that the Concept, through its dialectic, breaks through the limitation of this sphere, since it cannot rest content with an inadequate element, and necessarily passes over into a higher stage. (E 252a)

This may sound like a progressivist evolutionary view, and Hegel has been read that way, but the 'passing over' he is speaking of is not primarily a chronological process but rather the conceptual interrelation of the necessary concepts and types. As with geology, Hegel would find a chronological emergence philosophically uninteresting. What is important is the conceptual passing over of the moments of the Idea into one another, as shown in the types that appear and their place in the unity of Spirit. Those types are what is significant, not their empirical arising. Not that the form must come from Aristotle's 


\section{David Kolb}

prior actual representative of the same species, but that the form must be part of a logically necessary series of forms that is already in act. That series of forms is displayed differently in nature than in Spirit. The stages of Spirit's cultural development embody tensions and contradictions between internalised moments that lead to a society or culture changing internally. Nature, however, expresses the moments of the Idea separated and spread out in externality. Each expresses something of the Idea; each is needed and each is incomplete; all the stages are needed for the moments of the Idea to be posited. But in nature, more developed moments do not replace earlier ones; they add to them. Nature's display of necessary moments is accumulative, not inward turning and transforming. Nature cannot interiorise its own position. If it could, something would be lost, an external aspect of Spirit's being that is required for internality to develop.

Also, no matter how they are produced, natural beings come with already teleologically complete and necessary forms:

The production of the living thing is represented in general as an evolution out of chaos, where plant and animal life, organic and inorganic, were in a single unity. Or it was imagined that there was a general form of life and that this split up into the many species of plants and animals, into the races of mankind. But we must not assume a sensuous process of differentiation appearing in time, nor the existence in time of a universal Man [GeneralMensch] Nature's formations are determinate, bounded, and enter as such into existence. So that even if the earth was once in a state where it had no living things but only the chemical process, and so on, yet the moment the lightning of life strikes into matter, at once there is present a determinate, complete creature, as Minerva fully armed springs forth from the head of Man has not developed himself out of the animal, nor the animal out of the plant; each is at a single stroke what it is. In this individual, evolutionary changes do occur; at birth it is not yet complete, but is already the real possibility of all it is to become. The living thing is the point, this particular soul [Seele], subjectivity, infinite form, and thus immediately determined in and for itself. (E 339a)

Note that Hegel says 'Even if the earth was once in a state where it had no living things but only the chemical process...', so he is not completely opposed to a possible development of organic life over time, but that process would have to be under the general control of a set of a priori forms. He admits temporal origins for geological features, so he could admit a temporal origin for types of organic life. The series of types could arrive chronologically, but what is important is the set of types themselves, and how they relate to the overall Idea. Furthermore, that set of types cannot be abstracted form our experience of nature. It must be developed by thought independently: 
This type, however, cannot be furnished by experience, for it is experience which also presents these so-called monstrosities, deformities, intermediate products, etc. The fixed type rather presupposes the self-subsistence and dignity of the determination stemming from the Concept (E 250t)

As Hegel claims in the Logic, it is this self-constructing method alone that allows philosophy to be an objectively demonstrated science (Hegel 1969: 27-8).

But how detailed is the necessity of the Idea? The number of species of parrot? The number of legs on a spider? The shape of Africa? The colour of lions' pelt? The division between animals and plants? It is here that contingency officially arrives in Hegel's system. Even the more general concepts are contingent in their realisation in nature that is the empirical side of Spirit and history.

Hegel argues, in several ways but this is one, that since the categories are not in some Platonic heaven, they exist as wirklich, in action, at work in a realm of externality. Externality implies that qualities and traits are external to one another. A being will have more traits and qualities than those that are its categorial essence. Some of those will be the way its categorial essence is actualised, others will be just added on: ${ }^{10}$

The contradiction of the Idea, arising from the fact that, as Nature, it is external to itself, is more precisely this: that on the one hand there is the necessity of its forms which is generated by the Concept, and their rational determination in the organic totality; while on the other hand, there is their indifferent contingency and indeterminable irregularity. In the sphere of Nature contingency and determination from without has its right, and this contingency is at its greatest in the realm of concrete individual forms. The immediately concrete thing is a group of properties, external to one another and more or less indifferently related to each other. For that very reason, the simple subjectivity which exists for itself is also indifferent and abandons them to contingent and external determination. This is the impotence of Nature, that it preserves the determinations of the Concept only abstractly, and leaves their detailed specification to external determination. (E 250t) ${ }^{11}$

That there are animals is necessary, as is their possession of systems for mobility, perception, reproduction, nourishment. Their particular species and shapes are not necessary, though Hegel is not above seeing in those particularities echoes of essential divisions and mediations. No particular detail of a spider's anatomy or a bird's plumage is necessary. The more abstract features and systems limit the possibilities for the more contingent features but do not determine them. So Hegel is not in fact interested in origin of species except insofar as they instance new types of being (organic life, plants, animals) or as they introduce new kinds of differentiated internal organic systems. As 


\section{David Kolb}

long as evolutionary changes stayed within conceptual borders they would be merely empirical variation. The arising of another species of bird would be of no special interest. This would also be true for the change of one species into another as long as nothing conceptually new was involved. What would be significant would be if contingent changes caused new and conceptually necessary kinds of systems to appear. His concern is for the appearance in nature of all the necessary moments of the Idea.

\section{Conceptual Necessities and Natural Processes}

But if there is a historical becoming, which Hegel admits for geology and could admit for organics, then how does nature come to realise the moments of the Idea? What is that 'external determination' that produces the detailed specification of natural things? Is it their empirical causal history? How do physical processes relate to conceptual necessities?

In Hegel's text, there are examples where mechanical causes are suggested then rejected by Hegel in favour of processes that have no mechanical intermediaries. In such cases there is the direct action of the earth as a whole, the 'internal formative process' mentioned earlier and treated in the Encyclopaedia's discussion of chemical and electrical processes, which do not, for Hegel, result from still more basic atomic processes, but are nature's moments differentiating and relating one to another. ${ }^{12}$ One such example is the origin of springs:

We must not, therefore, explain the origin of inexhaustible springs by mechanically and quite superficially attributing them to percolation; any more than we must use a similar kind of explanation on the other side, to account for volcanoes and hot springs. Everywhere we see tracts, especially sandstone beds, which are always giving off moisture. I regard mountains, therefore, not as gatherers of rainwater which penetrates into them; on the contrary, the genuine springs which generate rivers like the Ganges, Rhone, and Rhine have an interior life, a striving and a stirring, like naiads; the earth discharges its abstractly fresh water which, in these outpourings, hastens to its concrete life, to the sea. $(E 341 a)^{13}$

Other examples where dialectical patterns happen directly without intermediary physical process include the origin of veins of metallic ores, the spontaneous generation of lower level life forms such as oceanic plankton ${ }^{14}$, and quasi-organic fossils. ${ }^{15}$ There are also processes that Hegel thinks do have mechanical intermediaries. He suggests, for example, that the shape of the continents results from a combination of the earth's magnetic field and the action of ocean currents, yet the result has a certain rationality: 
Its separation into water and land (which first unite with and permeate each other in the living subject), into continents and islands, and the shaping and crystallisation of these into valleys and mountains, all this belongs to its purely mechanical formation The concentration in the north results in the products, plants and animals, sharing a common nature. At the extremities, animal life is particularised and individualised into various genera and species which are peculiar to each continent. This appears at first to be accidental; but the activity of the Concept is to grasp as necessarily determined what to sense-consciousness appears as contingent A rational comprehension of the configuration as a whole would have to consider the fixed land formations in comparison with the ocean currents rather than with the oceans, i.e. with the expression of the free movement of the earth in its own self. (E 339a)

So, mechanical processes and Idea types are to be thought together. Now, all this action has to end up having produced the right types of rocks set in the right order. And, if Hegel were to admit organic evolution, it would have to have produced the right spectrum of life. A necessary set of types is to arise through contingent processes. This is where the issues from the Intelligent Design controversy reappear. If the rocks are to show necessary moments of the Idea, and if they did have a causal history, what made sure that that history ended up with the rocks that could be analysed independently according to the Concept? The same question arises for living beings.

Is this a legitimate question? If we are curious about how things came to be the way they are, we seem to be presuming that other outcomes were possible. In what sense were these alternative histories 'possible'? Hegel is no dualist like the Plato criticised by Aristotle. Then how is typological necessity operative? One is tempted to ask: what kind of causality is being exercised? But this is indeed a bad question; here are not two entities involved. Nature is the existence and actualisation, the working, of the Idea, not something else that the Idea is working over. ${ }^{16}$ It is embodiment defining possibility, setting parameters. Not restricting but opening the field of possibility. That field is finite; only abstraction makes it seem larger. We imagine other possible outcomes, but were they really possible? Many things seem possible when abstracted from their context, but closer thought shows what the real possibilities are:

Our picture-thought is at first disposed to see in possibility the richer and more comprehensive, in actuality the poorer and narrower category. Everything, it is said, is possible, but everything which is possible is not on that account actual. In real truth, however, if we deal with them as thoughts, actuality is the more comprehensive, because it is the concrete thought which includes possibility as an abstract element. . . [To see something as abstractly possible] nothing is required except to separate it 


\section{David Kolb}

from the relations in which it stands. Hence any content, however absurd and nonsensical, can be viewed as possible. It is possible that the moon might fall upon the earth tonight; for the moon is a body separate from the earth - and may as well fall down upon it as a stone thrown into the air does. It is possible that the Sultan may become Pope; for, being a man, he may be converted to the Christian faith, may become a Catholic priest, and so on. The less education a man has, or, in other words, the less he knows of the specific connections of the objects to which he directs his observations, the greater is his tendency to launch out into all sorts of empty possibilities (E 143a).

As opposed to such abstractions, real possibility is available only when all the required conditions have been assembled. Then something really is possible, but then it has also become necessary. So estimating what is really possible means taking into account the actual configuration of things as well as their innate powers and dispositions. With Spinoza rather than Leibniz, Hegel insists that actuality is not a selection from a wider set of general possibilities.

The question, then, is whether variant natural histories were ever really possible that would have led to very different sets of high level natural types. Hegel would not think so. There could have been great variety in the contingent details, but not in the major conceptually necessary types of natural phenomena and organic systems. But if the conceptual takes such precedence, how does this happen in the real world'?

How do we get from empirically separate causes and effects to unified conceptual content? Or, more properly, how do we get from self-differentiating conceptual content to empirical causes and effects? The answer is that the types define the possibility and the powers of things. But how? Are there some added causal factors at work?

Many have seen Hegel as providing such additional factors. In his 1893 review of a book on Hegel and Darwin, F. S. C. Schiller claimed that natural selection by itself could not produce the ordered nature we see around us:

As a matter of fact, evolution resulted in not a chaos of unrelated organisms, resembling one another only in their capacity to survive, but a hierarchy of beings capable of being grouped historically and morphologically in regular gradations under common principles. But did natural selection tell us that would be the case? Assuredly not. If, then, we are to get any comfort out of Evolution, it must be because there is more in it than natural selection, and it is that overplus which is of real philosophic importance. (Schiller 1893: 587-88)

Schiller saw this 'more' in the evident teleology found in the actual history of the evolutionary process. ${ }^{17}$ This has been echoed in recent discussions of Hegel and Darwin 
in Harris (1998) and Dahlstrom (1998), both of whom associate Hegel with a tendency to self-organisation and increasing complexity that leads to the development of conscious beings. While Hegel would surely agree that the development of conscious beings is not a chance occurrence, the language used by Harris and Dahlstrom either suggests mysterious extra causal factors or leaves undefined just how Concept and Spirit are involved in the process.

The key, I think, is to see that the requisite content is already there, working, in act. Again with Spinoza, Hegel insists that there are larger conceptual necessities actualising themselves not as separate super-things but through defining the forces and powers of natural individuals. The Concept is not an indefinite potentiality that needs some Aristotelian prior actuality to draw it out. In Aristotelian terms the activity of the Idea is more like an energeia, movement in a circle always already actual, than it is like an entelecheia, a movement from potentiality towards a goal. Nature does not so much contain a teleology towards higher developments as an already actual expression of the moments of the Concept, but an expression that is in the beginning too abstract and immediate. That Conceptual content is actual, working, and always already divided. It shows in the initial division between the overall unity of space and its points, between the separate pieces of matter and its overall unity expressed through gravity. Universal and particular are already working in their complex dance, but still expressed abstractly, without sufficient mediation.

It would take a review of the whole doctrine of Essence, the second part of Hegel's Logic, to see how Hegel tries to justify such claims. At each level of essence, we find the unity of a content being expressed as a union of inner and outer. At each stage some primacy is being asserted for inner or outer aspects, but that primacy keeps collapsing into a unified content that differentiates itself and exists only in that differentiation. In the third section of the Logic, the Essence dualities of form and matter, cause and effect, and so on, give way to the triad universal/particular/individual, which is about conceptual connections and developments, not causal or empirical processes. Empirical processes reappear in the sections on mechanism, chemism, teleology, but now expressed as and expressing conceptual connections.

In the 'Essence' section, Hegel argues that causes and effects share a content; there is nothing in the cause (as cause) that is not in the effect (as effect), and vice versa. Of course as independent entities the cause and the effect have other qualities and traits than those involved in the causal relation. But also, as independent entities with their own qualities, each is both active and passive, both cause and effect. Effects react on causes. What appears at first as a bad infinity of cause-effect links trailing off to past and future turns out to be a repetition of the same circular motions of reciprocal interaction, which replaces the linear notion of a one-way effect. Each side of the reciprocal interaction needs the other side, and neither has primacy.

Reciprocity, Hegel says, is the usual first escape from bad infinities, but it needs to be understood as an expression of a deeper unity. He argues that reciprocity expresses a 


\section{David Kolb}

unity of content that exists only through this division and interaction. This is clearer in the case of social unities that exist through the explicit intermediation of differentiated social roles and practices, but Hegel means it to apply to nature as well:

In historical research the question may be raised in a first form, whether the character and manners of a nation are the cause of its constitution and its laws, or if they are not rather the effect. Then, as the second step, the character and manners on one side and the constitution and laws on the other are conceived on the principle of reciprocity: and in that case the cause in the same connection as it is a cause will at the same time be an effect, and vice versa. The same thing is done in the study of Nature, and especially of living organisms. There the several organs and functions are similarly seen to stand to each other in the relation of reciprocity [ ... ] If we get no further than studying a given content under the point of view of reciprocity, we are taking up an attitude which leaves matters utterly incomprehensible. We are left with a mere dry fact, and the call for mediation, which is the chief motive in applying the relation of causality, is still unanswered [ ... ] To make, for example, the manners of the Spartans the cause of their constitution and their constitution conversely the cause of their manners, may no doubt be in a way correct. But, as we have comprehended neither the manners nor the constitution of the nation, the result of such reflections can never be final or satisfactory. The satisfactory point will be reached only when these two, as well as all other, special aspects of Spartan life and Spartan history are seen to be founded in this Concept. (E 156a)

In the end 'the link of necessity qua necessity is identity' $(E 157 t)^{18}$. For Hegel there are no Humean independent atomic entities to build up from. They exist only as moments of a process that itself exists only through their separation and interaction. The conceptual necessities of that process define the possibilities and powers that the seemingly independent entities possess and exercise. Only in the act of being taken up into a mediated unity does anything immediate exist, and it exists as the actualisation of a higher content and whole. That whole is a unity that can only be and be unified when it is divided and re-appropriated. No extra or extrinsic causal factors are required, only the natures and powers of actual natural beings.

\section{Hegel and Evolution Today}

Hegel could affirm that life has an empirical history of emergence, as he does with geological formations. But there are still significant differences between Hegel and Darwin. Some of them, though, are less than they seem. 
One difference from today is that Hegel's notion of species is still morphological and Aristotelian, not population based. However, this could be handled by assigning the spheres of contingency. Hegel is more concerned with larger kinds of being, and with the conceptually necessary features an organism must have, not with what species exist and where they come from. So a population concept of species could be worked into his theory as contingent realisation of the higher level concepts and systems.

Another difference is that Hegel's discussion presumes a notion of causality that is more Aristotelian than that found in scientific and philosophical theories that stem from the empiricists. Hegel sees causality as one entity having the power to transfer content to another. This is Aristotelian sharing of form and content. He does not see causal laws as statistical regularities connecting logically separate events. There is no way to fit Hegel's notion of causality into a Humean scheme. However, perhaps one could approach Humean event causation by emphasising what Hegel says about 'real possibility.' When the conditions are complete, the entity arises (see E 147-8). If the conditions and the effect were specified as sets of events, something like Humean causation would be described. This could accommodate the idea that sets of events cause other sets of events, though it would still not be empiricism, since Hegel would insist on a unified content expressing itself, and the separate events would have a necessary relation that Hume would deny. On the other hand, perhaps it is not necessary to stick to Humean causality; more Aristotelian notions of causality are reappearing today; talk of powers, dispositions, etc. is no longer forbidden. ${ }^{19}$

A third difference results from Hegel's refusal to admit that large cultural and historical changes can fully result from small contingent events. If the Roman Republic collapses, this is not due to the contingent personality of Julius Caesar. Structural tensions and contradictions in the underlying social unity provide the underlying conditions for the change that Caesar triggers. However, in nature, where movement to a different level does not replace the former level but supplements it, Hegel might allow that small contingencies could bring about large developments of new kinds of beings.

A more significant difference concerns uniformitarianism. Hegel would likely want to locate evolutionary changes in a past that is over, parallel to what he claims for geological history. Historical changes would have revealed the full repertory of types and moments. He could imagine evolution going on today as affecting the details of species and traits, but he would not want to accept that nature was not finished manifesting aspects of the Idea for spirit to take up. Current evolutionary theory argues that evolution continues. Could it then produce something new and as different as animals are from plants? Hegel would not want that to be possible. This issue parallels the debates over the extent to which Hegel is committed to the 'end of history' thesis that all the essential moments and forms of spirit's social development are now present, though contingent events will continue.

The most significant difference, the one that couldn't be given up, the one that puts Hegel between Intelligent Design and Darwin, is his claim that organisms have 


\section{David Kolb}

unified forms defining the possibilities that get contingently realised. For Hegel the issue is not the empirical origin of organic types but their necessary internal unity and rationality. Is this even an issue for Darwinism? The changing conditions that trigger natural selection are external and contingent. What appear to be unified forms of evolved creatures were assembled from earlier traits that may originally have been selected for quite different purposes. A trait might develop through selection for one function, then be turned in a new direction by selection for a new function that contingently arises. Dinosaur skin scales might develop into feathers for heat retention, then turn out to be useful for extending leaps or helping climbing, and be selected for new features that lead to flying birds. The very form of the organism and the unity of its systems are seen as the resultants of contingent happenings, without any conceptual necessities. The issue is whether the given facts of such reciprocal interactions need to be understood and comprehended in a deeper way, as Hegel claims with the Sparta example. There is also a more general issue concerning the nature of possibility: Is novelty the unfolding of conceptual necessity, or is it an irruption beyond any previous disposition or algorithm?20

So Hegel does stand apart from a Darwinism that implies a loose and purely consequential notion of form and unity. We shouldn't be surprised if their difference comes down to the unity and status of form in a holistic rationalism versus an atomic empiricism. ${ }^{21}$

\section{David Kolb}

Bates College

davkolb@gmail.com

www.dkolb.org

\section{Notes}

\footnotetext{
${ }^{1}$ Abbreviations:

E: Hegel, G. W. F. (1970), Hegel's Philosophy of Nature. A. V. Miller tr., Oxford: Clarendon Press. Excerpts from Hegel's Encyclopaedia are referenced by paragraph and are marked with an 'a' if they are from the additions to Hegel's text made after his death by adding material from student notes on his lectures in Berlin and with a ' $\mathrm{t}$ ' if they are from the text he published during his lifetime. Entries marked with a 'J' are from Hegel's early lectures at Jena in 1805-6. I have modified some of the translations. Another translation with extensive and useful annotations can be found in Petry 1970.

${ }^{2}$ For instance, while Aristotle does describe what he takes to be the best state (see Politics vii and viii), he also describes ways of causing and preventing revolutions in all the different kinds of states. (Politics v). All Aristotle references are taken from Aristotle 1941, the title is followed by reference to the book in Roman numerals.

${ }^{3}$ In the text I set aside interpretations of Hegel that make him a straight theological thinker or a Neo-Platonist for whom there is a cosmic mind present and active 'before' nature. Nor, despite his terminology of 'the Idea' and 'the Concept' does Hegel have an artistic designer behind nature.
} 
${ }^{4}$ In his Philosophy of Nature lectures Hegel cited discoveries in Asia and in Americas, but the details of the rock strata and types he discusses are mostly based on northern Europe. See Petry 1970 for descriptions of Hegel's sources in the contemporary geological literature.

${ }^{5}$ In this discussion I use Concept to translate Hegel's Begriff, active comprehending of and as part of the Idea, the totality of thought determinations including their own self-reflection.

${ }^{6}$ For instance, 'The physical organization of the earth, as immediate, does not begin with the simple, enveloped form of the germ, but with a coming-out [Ausgang] which has fallen apart into a duality, into the concrete granitic principle and the calcareous principle: the former is the core of mountains in which the triad of moments is displayed in an already developed state, while the latter is the difference which has been reduced to neutrality. The development of the moments of the first principle into specific formations goes through a series of stages in which the further forms are partly transitional, the granitic principle remaining the basis, only more unlike and unformed within itself; partly a development of its moments in to a more determinate difference and into more abstract mineral moments such as metals and fossil objects generally, until the development loses itself in mechanical stratifications and alluvial terrains lacking any immanent formative process. Side by side with this proceeds the development of the other, the neutral principle, partly into weaker transformations and partly, in combination with the granitic principle, into formations ranging from concrescent forms down to merely external mixtures' ( $E$ $340 \mathrm{t})$

7 Could there have been no Caesar or anyone else, and Spirit become stalled? Not retrospectively, since Spirit's self-comprehension has now developed. During the process of development, though, a 'stall' could go on for a long time, as Hegel thinks it has in China, but Hegel would say that though no one in the stalled period could quite see how, the tensions and contradictions would be still there waiting for contingent events to bring resolution and progress. There would be directed, teleological pressure for change. This pressure would come from the tensions and contradictions built into the actualisation of moments of the Idea that are not yet fully self-mediated. (It is not clear whether Hegel is being consistent when he claims that China, India, and Africa have become stalled at different stages of development. Though they embody historical Spirit, they now exist scattered about in space as do kinds of rocks and species of animals, expressing moments of the Idea, until they are assimilated into the developing global civil society.)

${ }^{8}$ See also the discussion of evolution and emanation in $E 252$ a.

9 Hegel references by name Lamark's work on invertebrates but not his ideas about evolution. Petry says that 'although the work of Wolff, Pander and von Baer outdated eighteenth century speculations on embryology and evolution ... Hegel seems to have been completely ignorant of it' (Petry 1970: 3: 231).

${ }^{10}$ This is related to the atomon eidos issue that goes back to Plato: just how detailed can or should the set of Forms be, considering that they cannot encompass all the infinite particularity of nature

${ }^{11}$ Aboulafia (1980) proposes Hegel's notion of contingency as a way to conceptualise Darwinian evolution. Contingent events are those that have no inner necessity or self-determination; through natural selection a set of contingent changes can, in conjunction with the environment, acquire inner necessity as a new species reproduces itself. This is an ingenious model, but it does not deal sufficiently with the difference in levels of generality. Even once a species is established there is no necessity from the Idea for most of its detailed qualities and quantities, only for it general structure and systems. Aboulafia, however, is not so much trying to interpret Hegel as to develop from Hegel a naturalistic model of evolution for Marxism, one that ignores the Idea.

${ }^{12}$ In some respects Hegel's direct action, where nature's moments differentiate and relate to one another, resemble Aristotle's idea that the four elements can transform into one another. 


\section{David Kolb}

${ }^{13}$ See too: 'Drying-out is supposed to have caused a fissure, a crevice in the rock into which the metallic solution flowed: this ... provides a very plausible explanation of the subsequent closingup of such rock-wounds. But it is a thoughtless conjecture; the relationship is not mechanical but is, in truth, physical, one in which the parts of the totality simplify themselves and sublate their developed determinate being, and for this very reason now expel it in abstracted form' (E 340a). ${ }^{14}$ 'This universal vitality is an organic life which inwardly stimulates itself, acts as a stimulus on its own self. The sea, which is something other than fresh and salt water ... is concrete salinity as an organic being which reveals itself at all points as procreative. That immediate being of the organism as genus is equally the outcome of sheer mediation through the non-organic world: it exists only through this otherness, this antithesis to itself as abstract universality; it is the genus which has been released from the individuality. But because that abstract universality is in its own self also life, it makes the transition through its own self to organic being in the generatio aequivoca; in general, the existence of organic being is the act of the whole earth, in which it individualises and contracts itself, the reflection-into-self of the universal. But equally it becomes a stabilised reflectedness into-self; and the higher plants and animals are this established reflectedness-into-self, which does not shoot up out of the earth like fungi, like unindividualised jelly or lichens which are only organic life in general'(E 341a).

15 'It is easy enough to postulate here the earlier existence of an organic world which was submerged by water. But then where did this world come from? It has arisen out of the Earth, but not historically; it perpetually proceeds from the Earth and has its substance in it. These organic forms, especially where they occur singly and do not constitute the entire rock-mass, are present where beds pass over into one another. The boundary where the moments, which processless Nature lets fall apart, are posited in a unity, is pre-eminently the site of organic forms, of petrifactions, and of those products which are neither animal nor plant forms, but which transcend the crystalline forms and are playful essays in organic formation' (E 340a).

16 'The Concept is not present as something conceived or imagined, while the thing stands over against the thinker and is fashioned by him; the Concept has not the form of consciousness but is immediately in the element of being, not detached from it. The Concept has the material for its work, where the moments of the organic are present in their totality; the question is not of a universal life of Nature, of Nature being everywhere alive, but of the essence of life: this essence is to be comprehended, to be exhibited in the moments of its actuality or totality, and these moments are to be demonstrated' (E 340a).

${ }^{17}$ Schiller, who reads Hegel in terms of the realism/idealism controversies of his day, does not see him as fitting in with Darwin: Nor, again, is Hegelianism a philosophy that can utilise Evolutionism in any shape or form. For if there is any universally admitted presupposition of modern Evolutionism, it is the reality of the time-process, which is assumed in every use of an historical method Evolutionism, if it means anything, asserts the reality of time, which is just what Hegelianism cannot and will not concede. Not only is Hegel's Evolution not a time process, but it leaves no room for such a process, except as a psychological illusion in 'finite minds' (Schiller 1893: 589).

18 'This pure self-reciprocation is therefore Necessity unveiled or realised. The link of necessity qua necessity is identity, as still inward and concealed, because it is the identity of what are esteemed actual things. The circulation of substance through causality and reciprocity therefore only expressly makes out or states that self-subsistence is the infinite negative self-relation - a relation negative in general, for in it the act of distinguishing and intermediating becomes a primariness of actual things independent one against the other - and infinite self-relation, because their independence only lies in their identity' (E 157t).

${ }^{19}$ See Cartwright (1983:1999) for her arguments against empiricist 'laws of nature,' and a defense of causal powers. The 2006 Central APA featured an invited symposium on 'The Metaphysics of Causality' where the principal speaker will argue for a causal powers theory that accepts 
necessary connections between causes and events through powers that transfer qualities at a different level than that of Humean events.

${ }^{20}$ Hegel would argue that in human history novelty stays within an overall conceptual necessity, but when novelty arises it is beyond any algorithm or recognised possibilities within the prior cultural system that it revolutionises. If he were to affirm organic evolution, then in natural history he could say that new types would appear that were beyond what one might have predicted on the basis of what was there earlier, but which were still within the possibilities opened by the powers already present. Nature does not make predictions and set up norms as does human culture, so there would have been in nature no prior projection of a system of uniformities that was now revolutionised

${ }^{21}$ Without holism would there be there any question here? Much of current philosophy (both Analytic and Continental) tends toward epistemological but not ontological holisms. Hegel would reject that dichotomy. 